\title{
The Formation of the Structure of the Alloys of the Tin- Zinc System upon High-Speed Solidification
}

\author{
V. G. Shepelevich ${ }^{a,} *$ and D. A. Zernitsa ${ }^{b}$ \\ a Belarus State University, Minsk, 220030 Republic of Belarus \\ ${ }^{b}$ Shamyakin State Pedagogical University, Mozyr, 247760 Republic of Belarus \\ *e-mail: shepelevich@bsu.by \\ Received May 21, 2020; revised July 3, 2020; accepted September 29, 2020
}

\begin{abstract}
The results of the study of the parameters of the structure of the fast-solidificated foil of hypoeutectic, eutectic, and hypereutectic alloys of the Sn-Zn system containing 4.4, 8.8, and $15 \mathrm{wt} \% \mathrm{Zn}$ are presented. The fast-solidificated foil consists of equiaxial zinc particles and a supersaturated solid solution of tin. The zinc particles are uniformly distributed in the foil, which is induced by the formation of a supercooled and supersaturated liquid solution and its subsequent spinodal decomposition. The tin- and zinc-enriched regions of the liquid solution transform to crystalline phase nuclei. The volume fraction of zinc particles, the mean chord of the random secants on the sections of the zinc particles, and the specific surface of the inter-phase boundary formed by zinc and tin increase with the increase in the concentration of zinc in the alloys under study. The foil of the Sn-Zn alloys has a microcrystalline structure, in which crystallographic texture of the grains is observed. The formation of the (100) texture of tin and (0001) texture of zinc is observed. The fastsolidificated foils of the alloys are in an unstable state, which leads to the decomposition of the supersaturated solid solution, dissolution of small particles, and growth of large particles. Annealing at $180^{\circ} \mathrm{C}$ for $22 \mathrm{~h}$ induces an increase in the mean chord of the sections of the zinc particles and volume of the zinc particles and a decrease in the specific surface of the interphase boundary.
\end{abstract}

Keywords: high-speed solidification, foil, Sn-Zn alloy, annealing, microstructure, texture DOI: $10.1134 / \mathrm{S} 2075113321040407$

\section{INTRODUCTION}

Achieving a reliable soldered joint without using harmful lead-based additives prohibited by the Restriction of Hazardous Substances (RoHS) Directive of the Council of Europe [1] is possible owing to tin-zinc alloys that find wide application in industry [2]. A eutectic $\mathrm{Sn}-\mathrm{Zn}$ solder is of interest because of its low melting point $\left(198.5^{\circ} \mathrm{C}\right)$ which is close to that of a tinlead alloy $\left(183^{\circ} \mathrm{C}\right)[3,4]$ and higher microhard-ness and tensile strength, which is confirmed by the results of the tests of the alloys of the $\mathrm{Sn}-\mathrm{Zn}$ system obtained at low rates of cooling (up to $278 \mathrm{~K} / \mathrm{s}$ ) $[5,6]$.

In recent decades, unconventional methods of preparation of alloys have been actively developed, including high-speed solidification [7]. Solid solution crystals nonuniform in composition are formed at low rates of cooling [4, 8-10]. Increasing the rate of cool-ing to $10^{6} \mathrm{~K} / \mathrm{s}$ makes it possible to suppress diffusion in the liquid solution, increase the degree of homogene-ity of the alloys, and obtain abnormal supersaturation of the solid solution, which was observed in [11-14]. The expansion of the solubility limit of the compo-nents as a result of the high rates of cooling $\left(10^{5}-10^{6} \mathrm{~K} / \mathrm{s}\right)$ is associated with the deceleration or suppression of the origin of the second phase [15] and can be used for improving the characteristics of the materials which cannot be reached at low rates of cooling [16].

A eutectic transformation occurs in a Sn-8.8 wt \% $\mathrm{Zn}$ alloy, and the structure of the eutectic being formed substantially depends on the crystallization conditions. Despite a whole series of studies of the alloys of the binary Sn-Zn system obtained at low and medium rates of cooling, study of the foils of $\mathrm{Sn}-\mathrm{Zn}$ alloys with various concentrations upon high-speed solidification is scarce in the published sources. In this connection, the investigation of the structure of the foils of the $\mathrm{Sn}-\mathrm{Zn}$ alloys obtained at ultrahigh rates of cooling is relevant and is of scientific and practical importance. This work describes the results of the studies of the structure of the foils of a eutectic alloy as well as hypoeutectic and hypereutectic alloys contain-ing $4.4 \mathrm{wt} \% \mathrm{Zn}$ and $15 \mathrm{wt} \% \mathrm{Zn}$, respectively.

\section{EXPERIMENTAL}

The alloys of the Sn-Zn system were obtained by fusing the components in a quartz ampoule followed by cooling at a rate of $10^{2} \mathrm{~K} / \mathrm{s}$ upon pouring into a graphite mold [17]. A piece of the alloy with a weight 

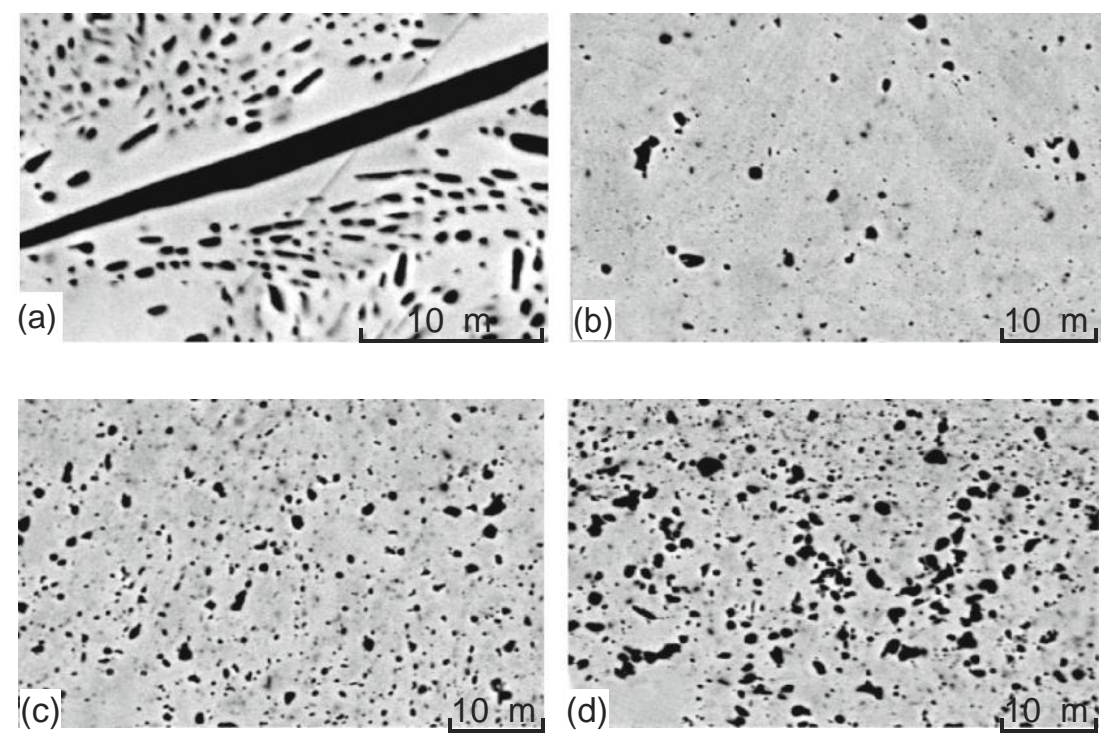

Fig. 1. Image of the microstructure of the (a) bulk sample with the composition $\mathrm{Sn}-10 \mathrm{wt} \% \mathrm{Zn}$ and (b-d) fastconsolidated foils of the alloys containing (b) 4.4 , (c) 8.8 , and (d) $15 \mathrm{wt} \% \mathrm{Zn}$.

of $\approx 0.2 \mathrm{~g}$ was repeatedly melted in a furnace and injected onto the internal polished surface of a fastrotating copper cylinder with a diameter of $20 \mathrm{~cm}$ $[18,19]$. The rate of cooling of the melt reached at least $5 \times 10^{5} \mathrm{~K} / \mathrm{s}$ [20]. The solidificated alloy had a shape of a foil, the length of which reached $15 \mathrm{~cm}$ and the width was $10 \mathrm{~mm}$. A foil with a thickness of 30-100 $\mu \mathrm{m}$ was used when studying the structure.

The structure of the fast-solidificated foil was studied on a LEO 1455 VP scanning microscope (Carl Zeiss, Germany) equipped with an electron probe microanalysis accessory. The grain structure of the foils was studied by electron backscatter diffraction (EBSD) implemented using an HKL CHANNEL5 diffraction analysis accessory (Oxford Instruments, Great Britain) for a LEO 1455 VP scanning electron microscope. The metallographic analysis of the structure was performed by the method of random secants [21]. A DRON-3 X-ray diffractometer was used to study the texture of the foils. The texture was studied by the method of inverse pole figure processing; the pole densities of the diffraction lines were calculated by the Harris method [22]. Surface $A$ of the foil adja-cent to crystallizer in the process of solidification of the melt and surface $B$ in contact with the atmosphere were studied. The annealing of the foils was performed in a drying oven.

\section{RESULTS AND DISCUSSION}

The bulk samples of the eutectic alloy obtained at an average rate of cooling of the melt of $\approx 10^{2} \mathrm{~K} / \mathrm{s}$ had a two-phase structure consisting of the solid solutions of zinc and tin according to the X-ray diffraction analysis. Coarse zinc plates with a length of up to $100 \mu \mathrm{m}$ and a thickness of up to $15 \mu \mathrm{m}$ (Fig. 1a) were observed by scanning electron microscopy.

(a)

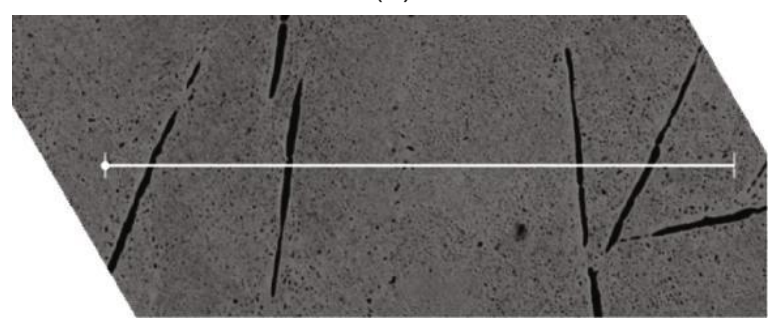

(b)

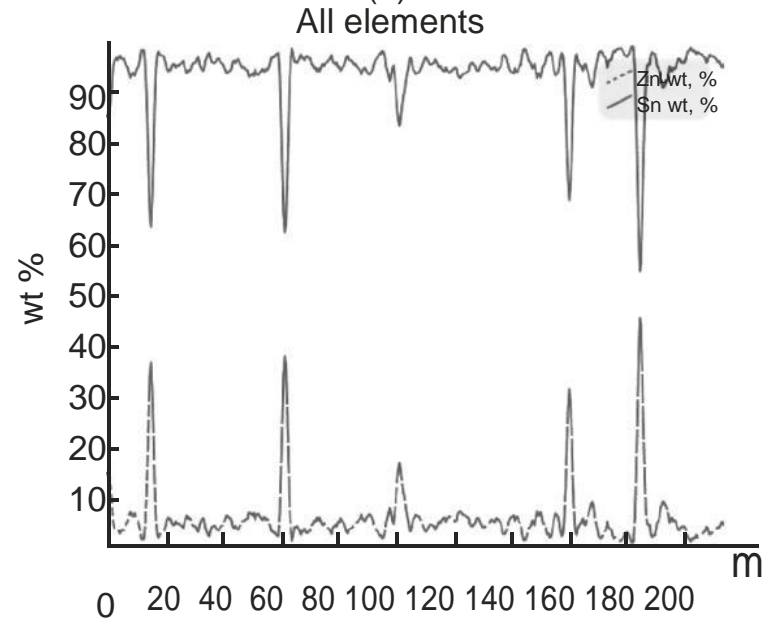

Fig. 2. Distribution of the intensity of the line $L_{\alpha}$ of the components upon scanning of an electron beam on the surface of a bulk sample with the composition Sn-10 wt \% Zn. 


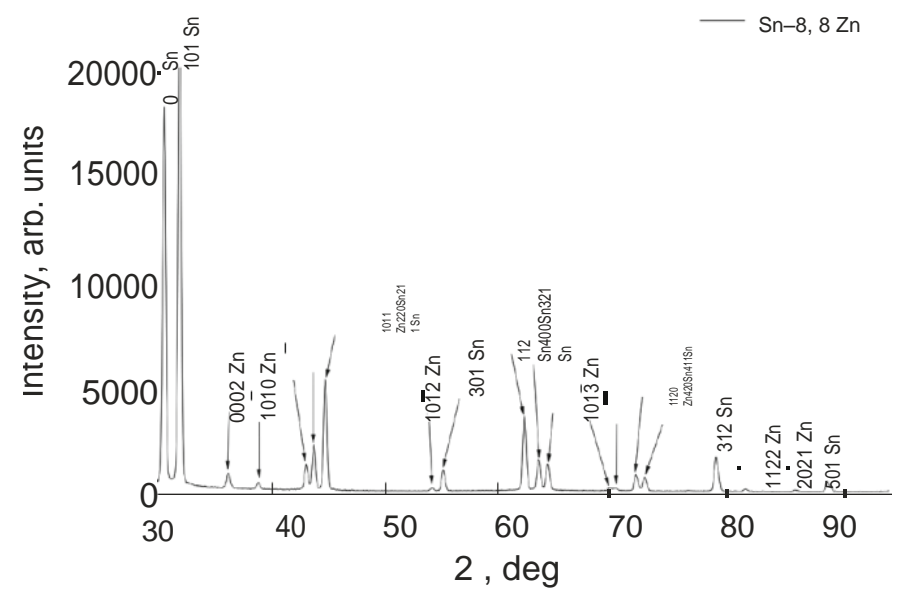

Fig. 3. X-ray diffraction pattern of the fast-solidificated foil of the Sn-8.8 wt \% Zn alloy.

X-ray microanalysis showed (Fig. 2) that the dark plates in the bulk sample were zinc, while the gray regions were a eutectic consisting of zinc and tin.

The X-ray diffraction pattern of the foil of the eutectic alloy is presented in Fig. 3; the diffraction lines of tin $(200,101,211$, etc.) and zinc $(0002,1010$, $10 \overline{1} 1,10 \overline{1} 2$, etc.) are observed in it; i.e., the fast-solidificated alloy consists of the solid solutions of tin and zinc.

The image of the microstructure of the foil of the eutectic alloy obtained by ultrafast solidification is presented in Fig. 1c. Equiaxial precipitates of zinc with a size of no more than $1.5 \mu \mathrm{m}$ are observed, which are uniformly distributed in the foil. There is no platelike structure in the foils of the eutectic alloy, which is very important because this improves the plastic properties and does not promote brittle fracture. The same structure is also formed in the fast-solidificated foils containing 4.4 and 15 wt $\% \mathrm{Zn}$ (see Figs. 1b, 1d). The values of the volume fraction of zinc $V_{Z n}$, mean chords of the random secants on the sections of zinc $d_{Z n}$, and specific surface of the interphase boundaries $S_{\text {IPB }}$ for the foils with different compositions are presented in Table 1.

An increase in the mean chord of the random secant on the sections of the zinc particles and the spe-cific surface of the interphase boundary with the increase in the concentration of zinc in the alloy is observed, which is determined by the increase in the number of the particles in the bulk.

The distribution of zinc particles in the fast-solidificated alloys by size groups is presented in Fig. 4 . The fraction of the chords of the random secants on the sections of the zinc particles monotonically decreases with the increase in the boundaries of the size groups. Here, the character of the change in the distribution of the chords is the same for all the alloys.

The formation of dispersed uniformly distributed zinc particles is determined by the significant super- cooling of the liquid phase that is supersaturated with both components in this case [23, 24]. Here, the dependence of the free energy of the liquid solution $F$ on the composition $c$ is W-shaped [24], and its decomposition occurs by the spinodal mechanism because the second derivative of free energy with respect to the concentration $\frac{d \stackrel{2}{F}}{<0}$. As a result, redistribution of $d c^{2}$ the components occurs throughout the entire volume of the melt, thus inducing the formation of the regions enriched in tin or zinc. The spinodal decomposition occurs throughout the entire volume. The regions enriched in tin or zinc promote the formation of the crystalline phase nuclei. Because of this, the precipitates of zinc are uniformly distributed in the fast-solidificated foil of the eutectic as well as in the alloys the composition of which is close to the eutectic composition.

Figure 5 presents an image of the grain structure of the solid solution of tin in the layer of the foil adjacent to the crystallizer for a Sn-8.8 wt \% Zn alloy. The fastsolidificated foils of the $\mathrm{Sn}-\mathrm{Zn}$ alloys are microcrystalline. Similar images of the grain structure are observed in the alloys containing 4.4 and $15 \mathrm{wt} \% \mathrm{Zn}$. The values of the mean chord of the random secants on the section of the tin grains $D_{\mathrm{Sn}}$ and the specific surface of the highangle boundaries of the grains $S_{H A B}$ presented in Table 2 are determined by the method of random secants. A monotonic decrease in $D_{S n}$ and an

Table 1. Values of the parameters of the microstructure of the fast-solidificated foils of the alloys of the $\mathrm{Sn}-\mathrm{Zn}$ system

\begin{tabular}{l|l|l|l}
\hline \multicolumn{1}{c|}{ Concentration of zinc, wt \% } & \multicolumn{1}{|c|}{4.4} & \multicolumn{1}{|c|}{8.8} & \multicolumn{1}{c}{15} \\
\hline Volume fraction of zinc & 0.038 & 0.052 & 0.10 \\
Mean chord of zinc $d, \mu \mathrm{m}$ & 0.30 & 0.32 & 0.41 \\
$\begin{array}{l}\text { Specific surface of the inter- } \\
\text { phase boundary } \underset{\mathrm{IPB}}{S}, \mu \mathrm{m}^{-1}\end{array}$ & 0.38 & 0.81 & 0.92 \\
\hline
\end{tabular}




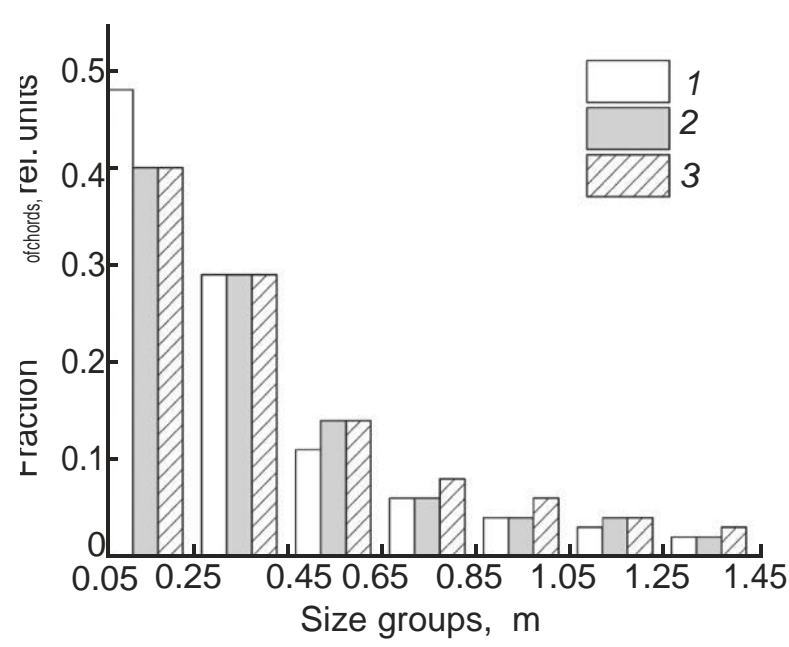

Fig. 4. Distribution of the chords of random secants on the sections of zinc by size groups in the fastsolidificated foils of the Sn-Zn alloys containing (1) 4.4 , (2) 8.8 , and (3) 15 wt \% Zn.

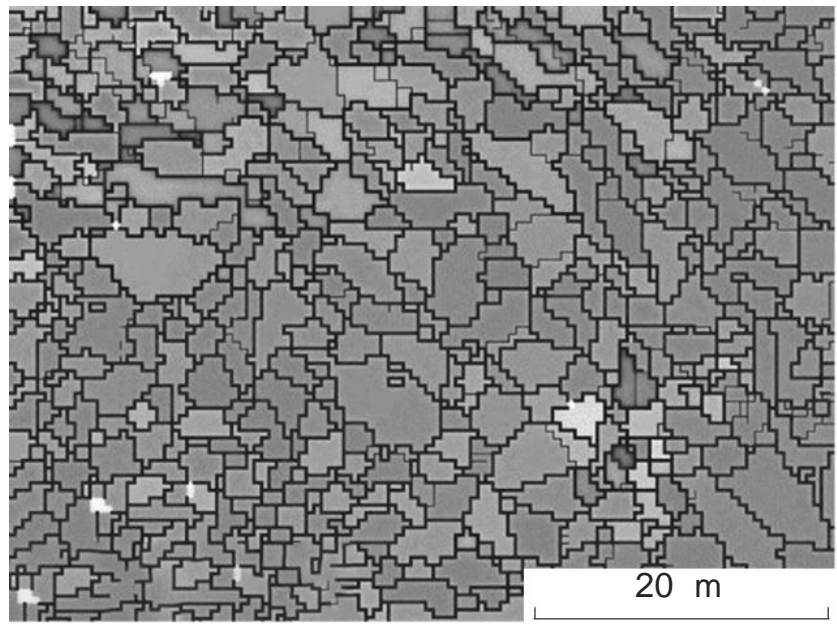

Fig. 5. Grain structure of the foil of the Sn-8.8 wt \% Zn alloy.

increase in $S_{\mathrm{HAB}}$ with the increase in the concentration of zinc in the alloys are observed.

The texture of the foils was studied by X-ray diffraction analysis; the pole densities were calculated by the Harris method for two sides of the foil. The results of the study are presented in Tables 3 and 4 . The high-

Table 2. Values of the parameters of the grain structure of the fast-solidificated foils of the alloys of the $\mathrm{Sn}-\mathrm{Zn}$ system

\begin{tabular}{l|c|c|c}
\hline \multirow{2}{*}{$\begin{array}{r}\text { Parameters of } \\
\text { the grain structure }\end{array}$} & \multicolumn{3}{|c}{ Concentration of zinc, wt \%; } \\
\cline { 2 - 4 } & 4.4 & 8.8 & 15 \\
\hline$D_{\mathrm{Sn}}, \mathrm{m}$ & 3.8 & 2.3 & 1.4 \\
$S_{\mathrm{HAB}}, \mu \mathrm{m}^{-1}$ & 0.53 & 0.85 & 1.5 \\
\hline
\end{tabular}

est value of the pole densities is due to line 0002 , which belongs to the phase of zinc, and line 200, which belongs to the phase of tin, which indicates the forma-tion of (0001) texture of $\mathrm{Zn}$ and (100) texture of $\mathrm{Sn}$ in layer $A$ of the foil adjacent to the crystallizer. Under the conditions of strong supercooling, the grains with the (0001) orientation of $\mathrm{Zn}$ and (100) orientation of $\mathrm{Sn}$ grow at the highest rate in the direction of heat removal, thus forming the texture observed in the foil [25-28]. As the crystallization front moves, the decrease in the heat flux promotes the weakening of the texture, which is confirmed by the less well-defined structure in layer $B$.

The fast-solidificated foil of the $\mathrm{Sn}-\mathrm{Zn}$ alloys under study is in an unstable state. The annealing of the foils induces a change in the microstructure of the precipitates of tin and zinc (Figs. 6a, 6b). Thus, isothermal annealing of the foil of the Sn-8.8 wt \% Zn alloy at 110 and $165^{\circ} \mathrm{C}$ leads to the redistribution of the zinc particles by size groups (see Fig. 6a). The most significant distribution of the chords of the random secants occurs as a result of annealing at $110^{\circ} \mathrm{C}$ for $4 \mathrm{~h}$. The fraction of the chords more substantially decreases in the minimum size groups, while it increases in the medium size groups. Moreover, addi-tional size groups appear for the chords positioned on the sections of the precipitates of tin. The temperature of annealing is high for the alloys under study because the eutectic temperature is $189^{\circ} \mathrm{C}$. Diffusion processes that promote the migration of the atoms of both phases actively occur during the annealing. The disso-lution of small and growth of large precipitates of the phases occurs [26].

Isothermal annealing of the foils of the Sn-8.8 wt $\% \mathrm{Zn}$ alloy at $180^{\circ} \mathrm{C}$ induces an increase in the mean chord $d_{Z n}$ of the random secants on the precipitates of zinc and volume fraction of zinc and a decrease in the specific surface of the interphase boundary SIPB. For example, the volume fraction of zinc increased twofold, the average grain size increased threefold, and the specific surface decreased twofold as a result of annealing for $20 \mathrm{~h}$. The changes in the parameters of

Table 3. Pole densities of the diffraction lines of tin of the foils of the alloys of the Sn-Zn system

\begin{tabular}{c|c|c|c|c}
\hline \multirow{2}{*}{ Diffraction lines } & \multicolumn{4}{|c}{ Concentration of zinc, wt \% } \\
\cline { 2 - 5 } & 4.4 & \multicolumn{2}{|c|}{8.8} & 15 \\
\cline { 2 - 5 } & surface A & surface $A$ & surface $B$ & surface A \\
\hline 200 & 5.0 & 3.6 & 1.1 & 2.5 \\
101 & 0.4 & 1.2 & 1.2 & 1.9 \\
220 & 0.1 & 0.1 & 0.9 & 0.4 \\
211 & 0.1 & 0.4 & 0.9 & 0.4 \\
301 & 0.2 & 0.1 & 1.1 & 0.2 \\
112 & 0.2 & 0.6 & 0.9 & 0.2 \\
\hline
\end{tabular}


Table 4. Pole densities of the diffraction lines of

\begin{tabular}{|c|c|c|c|c|}
\hline \multirow{3}{*}{ Diffraction lines } & \multicolumn{4}{|c|}{ zinc Concentration of zinc, wt \% } \\
\hline & \multirow{2}{*}{\begin{tabular}{|c|}
4.4 \\
surface $A$
\end{tabular}} & \multicolumn{2}{|c|}{8.8} & \multirow{2}{*}{\begin{tabular}{|c|}
15 \\
surface $A$
\end{tabular}} \\
\hline & & surface $A$ & surface $B$ & \\
\hline 0002 & 1.9 & 2.4 & 1.7 & 3.5 \\
\hline $10 \overline{1} 10$ & 1.2 & 2.3 & 0.8 & 2.9 \\
\hline $10 \overline{1} 1$ & 1.5 & 2.3 & 0.6 & 1.3 \\
\hline $10 \overline{2}$ & 0.0 & 0.0 & 0.8 & 0.0 \\
\hline $11 \overline{10}$ & 1.2 & 0.0 & 0.8 & 0.0 \\
\hline $11 \overline{1} 0$ & 1.3 & 0.0 & 1.1 & 0.0 \\
\hline $20^{-}+1$ & 0.9 & 0.0 & 1.4 & 0.0 \\
\hline
\end{tabular}

the microstructure of the foil of the Sn-8.8 wt \% Zn alloy that are observed indicate the decomposition of the supersaturated solid solution based on tin [29]. The occurring coalescence processes determine the

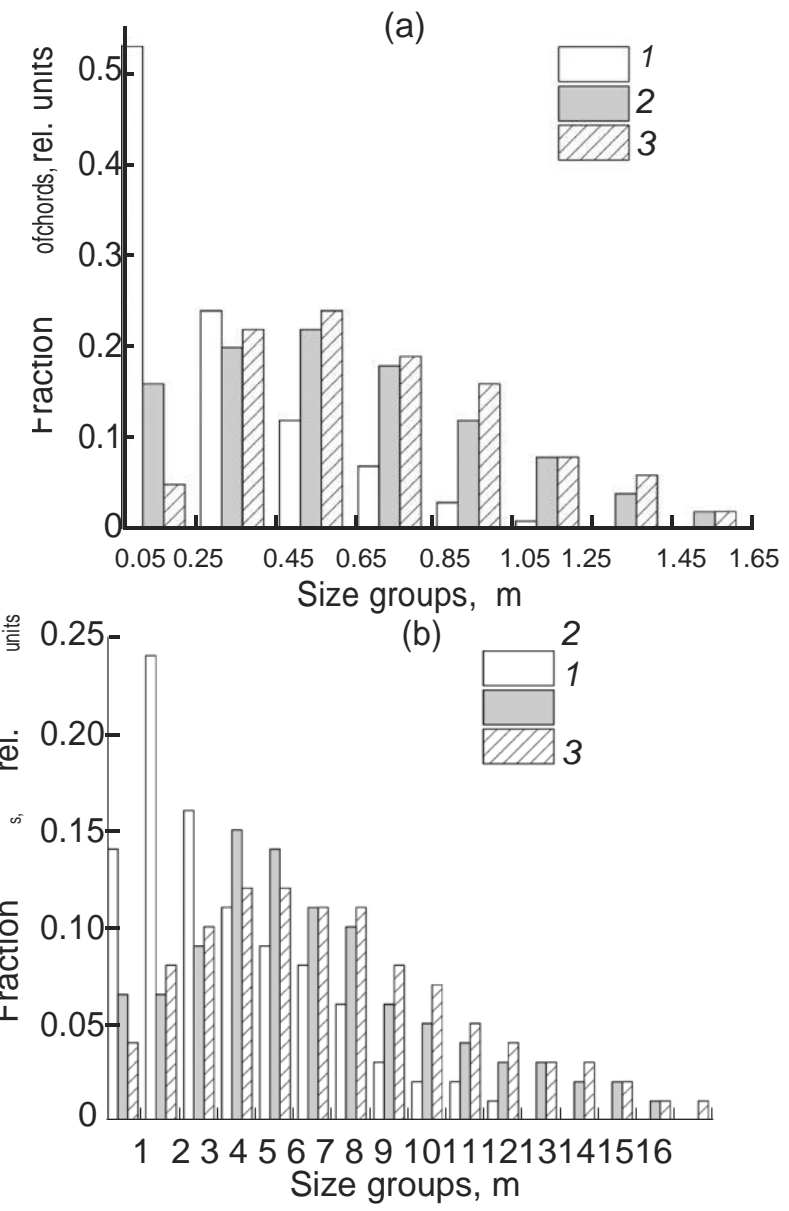

Fig. 6. Distribution of the chords of the random secants on the sections of the (a) zinc and (b) tin particles of the Sn- $8.8 \mathrm{wt} \% \mathrm{Zn}$ alloy in the (1) initial state and $(2,3)$ after $4 \mathrm{~h}$ at (2) 110 and (3) $165^{\circ} \mathrm{C}$. dissolution of the small precipitates and enlargement of the large precipitates, which is the reason for the increase in the mean chord $d_{\mathrm{Zn}}$ and the decrease in the specific surface of the interphase boundary $S_{\text {IPB }}[30]$.

\section{CONCLUSIONS}

Thus, the fast-solidificated foils of the eutectic alloy of the zinc-tin system as well as the alloys with the composition close to the eutectic composition are characterized by the uniform distribution of the dis-persed equiaxial zinc particles and absence of its rough plates, which improves the mechanical properties of the alloy and has great practical importance. A dis-persed structure is formed in the foils. Here, an increase in the mean chord of the random secants and a decrease in the specific surface of the interphase boundaries occur with the increase in the concentra-tion of zinc.

A monotonic 2.7-fold decrease in the average grain size $D_{\mathrm{Sn}}$ with the increase in the concentration of zinc in the fast-solidificated alloys is observed, and the spe-cific surface of the high-angle boundaries $S_{H A B}$ increases threefold. The formation of (100) texture of tin and (0001) texture of zinc in the fast-solidificated foils of the alloys under study is determined by the pre-dominant growth of the crystallites, in which the close-packed (100) plane of tin and (0001) plane of zinc are perpendicular to the direction of heat removal during the crystallization. The weakening of the above textures occurs as a result of a decrease in the degree of supercooling of the subsequent layer of the foil.

Annealing of the foils at $180^{\circ} \mathrm{C}$ is accompanied by an increase in the volume and size of the zinc particles and a decrease in the specific surface of the interphase boundaries.

\section{REFERENCES}

1. El Basaty, A.B., Deghady, A.M., and Eid, E.A., Influ-ence of small addition of antimony $(\mathrm{Sb})$ on thermal be-havior, microstructural and tensile properties of $\mathrm{Sn}-9.0 \mathrm{Zn}-0.5 \mathrm{Al} \mathrm{Pb}$-free solder alloy, Mater. Sci. Eng., A, 2017, vol. 701, pp. 245253. https://doi.org/10.1016/j.msea.2017.06.092

2. Kechin, V.A. and Lyublinskii, E.Ya., Tsinkovye splavy (Zinc Alloys), Moscow: Metallurgiya, 1986.

3. Lee, J.E., Kim, K.S., Suganuma, K., Takenaka, J., and Hagio, K., Interfacial properties of $\mathrm{Zn}-\mathrm{Sn}$ alloys as high temperature lead-free solder on Cu substrate, Ma-ter. Trans., 2005, vol. 46, no. 11, pp. 2413-2418. https://doi.org/10.2320/matertrans.46.2413

4. Saleh, A.A., A comparative experimental study of hy-poeutectic Sn-Zn solder alloys, Int. J. Mech. Eng. Technol., 2018, vol. 9, no. 6, pp. 909-915.

5. Liu, S., Xue, S., and Xue, P., Present status of Sn-Zn lead-free solders bearing alloying elements, J. Mater Sci.: Mater Electron., 2015, vol. 26, no. 7, pp. 4389-4411. https://doi.org/10.1007/s10854-014-2659-7 
6. Santos, W.L., Brito, C., Bertelli, F., et al., Microstructural development of hypoeutectic Zn-(10-40) wt\% Sn solder alloys and impacts of interphase spacing and macrosegregation pattern on hardness, J. Alloys Com-pd., 2015, vol. 647, pp. 989-996.

https://doi.org/10.1016/j.jallcom.2015.05.195

7. Shepelevich, V.G., Bystrozatverdevayushchie legko-plavkie splavy (Rapidly Solidified LightMelting Al-loys), Minsk: Belorus. Gos. Univ., 2015.

8. Chang, C.W. and Lin, K.L., High-temperature mechanical properties of $\mathrm{Zn}$-based high-temperature lead-free solders, J. Electron. Mater., 2019, vol. 48 , no. 1 , pp. $135-141$. https://doi.org/10.1007/s11664-018-6776-6

9. Yang, X., Hu, W., Yan, X., and Lei, Y., Microstructure and solderability of $\mathrm{Zn}-6 \mathrm{Al}-x \mathrm{Sn}$ solders, J. Electron. Mater., 2015, vol. 44, no. 4, pp. 1128-1133. https://doi.org/10.1007/s11664-015-3651-6

10. Song, J.M. and Lin, K.L., Behavior of intermetallics in liquid $\mathrm{Sn}-\mathrm{Zn}-\mathrm{Ag}$ solder alloys, J. Mater. Res., 2003, vol. 18, no. 9, pp. 2060-2067. https://doi.org/10.1557/jmr. 2003.0290

11. Kamal, M., Mazen, S.A., and El-Naggar, M.G., Effect of copper addition on some properties of rapidly solidi-fied leadfree Sn-10 wt\% Zn alloys, Radiat. Eff. Defects Solids, 2004, vol. 159, pp. 335-344. https://doi.org/10.1080/10420150412331272354

12. Wei, C., Liu, Y., Yu, L., Xu, R., Yang, K., and Gao, Z., Effects of thermal treatment on microstructure and microhardness of rapidly solidified $\mathrm{Sn}-\mathrm{Ag}-\mathrm{Zn}$ eutectic solder, Appl. Phys. A, 2009, vol. 95, no. 2, pp. 409-413. https://doi.org/10.1007/s00339-008-4886-3

13. Yan, J., Zhu, D., Liu, Y., and Xu, J., Effect of aging treatment on microstructural evolution of rapidly solid-ified eutectic Sn-Pb alloy powders, Appl. Sci., 2019, vol. 9, art. ID 392. https://doi.org/10.3390/app9030392

14. Akdeniz, M.V., Reid, C.N., and Wood, J.V., Structures in rapidly solidified zinc, Mater. Sci. Eng., 1988, vol. 98, pp. 321-323. https://doi.org/10.1016/0025-5416(88)90178-4

15. German, G., Sverkhbystraya zakalka zhidkikh splavov (Very Rapid Quenching of Liquid Alloys), Moscow: Metallurgiya, 1986.

16. Lozenko, V.V. and Shepelevich, V.G., Effect of ultrafast quenching on the structure and mechanical properties of the fast-hardened foil of $\mathrm{Zn}-\mathrm{Cd}$ alloys, Vestn. Belorus. Gos. Univ., Ser. 1: Fiz., Mat., Inform., 2006, no. 1, pp. 37-41. http://elib.bsu.by/handle/123456789/15913

17. Gusakova, O.V., Lozenko, V.V., and Shepelevich, V.G., Bystrozatverdevshie splavy tsinka (Rapidly Solidified Zinc Alloys), Minsk: RIVSh, 2016.
18. Lozenko, V.V. and Shepelevich, V.G., Zinc foils ob-tained by very rapid quenching from the melt, Materia-lovedenie, 2007, no. 7, pp. 32-36.

19. Shepelevich, V.G. and Gusakova, O.V., The effect of antimony alloying on the microstructure and the prop-erties of rapidly solidified alloy $\mathrm{Bi}-60 \mathrm{at} \% \mathrm{Sn}$, Inorg. Mater.: Appl. Res., 2020, vol. 11, pp. 2530. https://doi.org/10.1134/S2075113320010323

20. Miroshnichenko, I.S., Zakalka iz zhidkogo sostoyaniya (Quenching from the Liquid State), Moscow: Metal-lurgiya, 1982.

21. Saltykov, S.A., Stereometricheskaya metallografiya (ste-reologiya metallicheskikh materialov): Uchebnoye poso-bie dlya vuzov (Stereometric Metallography (Stereology of Metallic Materials): Guide for Universities), Mos-cow: Metallurgiya, 1976.

22. Rusakov, A.A., Rentgenografiya metallov (X-Ray Dif-fraction Analysis of Metals), Moscow: Atomizdat, 1977.

23. Martin, J.W. and Doherty, R.D., Stability of Microstructure in Metallic Systems, Cambridge Univ. Press, 1976.

24. Sokolovskaya, E.M. and Guzei, L.S., Metallokhimiya (Metal Chemistry), Moscow: Mosk. Gos. Univ., 1986.

25. Romanova, A.V. and Bukhalenko, V.V., Crystal structure of zinc quenched from the liquid state, Phys. Met. Metallogr., 1973, vol. 35, no. 6, pp. 185-186.

26. Shepelevich, V.G., Bystrozatverdevayushchie legko-plavkie splavy (Rapidly Solidified LightMelting Al-loys), Minsk: Belorus. Gos. Univ., 2015.

27. Lozenko, V.V. and Shepelevich, V.G., Grain and sub-grain structure of rapidly solidified $\mathrm{Zn}, \mathrm{Zn}-\mathrm{Cd}$, Zn-Sn, and Zn-Sb foils, Inorg. Mater., 2007, vol. 43 , no. 1 , pp. 20-24. https://doi.org/10.1134/S0020168507010062

28. Shepelevich, V.G. and Gusakova, O.V. Structure and properties of rapidly solidified $\mathrm{Sn}-\mathrm{Zn}$ foils, Inorg. Ma-ter., 2008, vol. 44, no. 5, pp. 485-489. https://doi.org/10.1134/S0020168508050105

29. Shepelevich, V.G. and Gusakova, O.V., Decomposi-tion of a supersaturated solid solution in thin foils of Sn-Bi alloys, Phys. Met. Metallogr., 2009 , vol. 108 , no. 3, pp. 292-297. https://doi.org/10.1134/S0031918X09090105

30. Shepelevich, V.G. and Zernitsa, D.A., The structure of rapidly solidified foil of the eutectic $\mathrm{Sn}-8.8 \mathrm{wt} . \% \mathrm{Zn}$ alloy, Zh. Belorus. Gos. Univ., Fiz., 2020, no. 1, pp. 6772. https://doi.org/10.33581/2520-2243-2020-1-67-72 